Mini Review

\title{
Electroanalytical Sensors for Synthetic Food Colorants Determination in Beverage. Period 2010-2018
}

\author{
Yun Yang ${ }^{*}$, Siyue Zhang, Shi Ren, \\ Department of Chemistry, College of Biotechnology and Food Science, Tianjin University of \\ Commerce, P.R. China \\ *E-mail: yyun1976@126.com
}

doi: $10.20964 / 2019.08 .41$

Received: 7 April 2019 / Accepted: 24 May 2019 / Published: 30 June 2019

\begin{abstract}
Synthetic colourants are widely used in the food industry, especially in beverages. The excessive intake of synthetic colourants can be harmful to human health. Therefore, it is necessary to establish a simple and rapid means of their analysis and detection for food safety management. Electrochemical analysis is a fast, safe and low-cost method. In this review, we summarized the literature on electrochemical detection of synthetic colourants from 2010 to 2018 and found that sensor design is primarily based on carbon materials. In this review, we also compare the properties of different materials and discuss the future directions of this field.
\end{abstract}

Keywords: Beverage; Electrochemistry; Food chemistry; Sensor; Analytical chemistry

\section{FULL TEXT}

(C) 2019 The Authors. Published by ESG (www.electrochemsci.org). This article is an open access article distributed under the terms and conditions of the Creative Commons Attribution license (http://creativecommons.org/licenses/by/4.0/). 